\title{
Stochastic Analysis and Forecasts of the Patterns of Speed, Acceleration, and Levels of Material Stock Accumulation in Society
}

\section{Supporting information}

Tomer Fishman ${ }^{\mathrm{a},{ }^{*}}$, Heinz Schandl, ${ }^{\mathrm{a}, \mathrm{b}}$, and Hiroki Tanikawa ${ }^{\mathrm{a}}$

${ }^{a}$ Nagoya University, Graduate School of Environmental Studies, D2 1(510) Furo-cho, Chikusa-ku, Nagoya, 464-8601 Japan.; ${ }^{\mathrm{b}}$ Commonwealth Scientific and Industrial Research Organisation (CSIRO), Black Mountain Laboratories, Clunies Ross Street, Acton, 2601 ACT, Australia.

* Corresponding author: Tomer Fishman, Nagoya University, Graduate School of Environmental Studies, D2 1(510) Furo-cho, Chikusa-ku, Nagoya, 464-8601 Japan. Telephone \& Fax +81-52-7893840. Email: tomer.fishman@nagoya-u.jp

Number of pages: 16. Number of figures: 47. Number of tables: 45 .

Contents:

1 Details of the ARIMA method $\quad$ S2

1.1 The ARIMA model $\quad$ S2

$\begin{array}{lll}1.2 & \text { Fitting and model selection procedures } & \text { S2 }\end{array}$

1.3 Examples using the material stock data $\quad \mathrm{S} 3$

2 Comparison of this study's stochastic forecasts with deterministic forecasts from $\quad$ S4 previous research

3 Visualization of the 3rd order of difference for Japan $\quad$ S5

4 ARIMA models for all 45 examined countries and the world $\quad$ S5

4.1 Category I - stationary speed (one country) S5

4.2 Category II - stationary acceleration (20 countries) S6

4.3 Category III - non-stationary acceleration, overall increasing acceleration (15 $\quad$ S11 countries + World)

4.4 Category IV- non-stationary acceleration, varying phases (8 countries) $\quad$ S15 


\section{Details of the ARIMA method}

\subsection{The ARIMA model}

ARIMA (Auto-Regressive Integrated Moving-Average) models are classified as ARIMA(p,d,q) where:

$p$ is the number of autoregressive (AR) terms

$d$ is the number of orders of difference

$q$ is the number of moving average (MA) terms

The ARIMA equation to be fitted is:

$$
\left(1-\phi_{1} B-\cdots-\phi_{p} B^{p}\right)(1-B)^{d} y_{t}=c+\left(1+\theta_{1} B+\cdots+\theta_{q} B^{q}\right) e_{t}
$$

Where:

$y_{t}$ is the value of the time series at time $t$,

$e_{t}$ is white noise,

$c$ is a constant,

$p, d$, and $q$ are as detailed above,

$\phi_{i}$ is the AR coefficient of lag $i$,

$\theta_{i}$ is the MA coefficient of lag $i$,

and $B$ is the backshift operator

The backshift operator simplifies the presentation of the equation and is defined as:

$$
\begin{gathered}
B y_{t}=y_{t-1} \\
B^{d} y_{t}=y_{t-d}
\end{gathered}
$$

Using the backshift operator, order of difference $d$ can be written as:

$$
(1-B)^{d} y_{t}
$$

\subsection{Fitting and model selection procedures}

Using the R statistics package, for each country and the world an ARIMA(p,d,q) model was fitted and selected using the Box-Jenkins approach as detailed in the references ${ }^{1,2}$ and without any modification to the procedure on our part, through the following steps:

(1) Identification of stationarity:

i. Stationarity of the original time series was checked using two independent statistical tests for unit roots: the Augmented Dickey-Fuller test and the Kwiatkowski-Phillips-SchmidtShin (KPSS) test.

ii. A unit root suggests that the series is not stationary. If a unit root was not detected by the statistical tests (i.e. statistically suggesting that the series is stationary) a visual check of the series was conducted to confirm that the series is indeed mean-reverting.

iii. If a unit root was detected or if the series was clearly not mean-reverting, differencing was done $\left(y_{t}-y_{t-1}\right)$ and the process was repeated with the differenced data series.

iv. This process was repeated until a stationary series was found at order of difference $D$ and the value of $d$ was determined.

(2) The number of Autoregression terms ( $p$ ) or Moving Average terms $(q)$, the values of their coefficients, and the inclusion of a constant, (i.e. the 'best fit' model) were selected from 
parsimonious candidate models by minimizing the Corrected Akaike's Information Criteria using R's forecast package functions auto.arima and Arima.

(3) Diagnosis for the absence of residual time series correlations was confirmed by the Ljung-Box Portmanteau test and autoregression and partial autoregression correlograms.

Full details of the ARIMA method, the model selection and fitting procedure, the statistical tests, and so on may all be found in the references.

\subsection{Examples using the material stock data}

Example 1.

The model for the Netherlands' speed of material stock accumulation is ARIMA(1,0,0):

$$
(1-0.674 B)(1-B)^{0} y_{t}=45139172+e_{t}
$$

Which can be rearranged and rewritten as:

$$
\begin{aligned}
& y_{t}-0.674 B y_{t}=45139172+e_{t} \\
& y_{t}=45139172+0.674 y_{t-1}+e_{t}
\end{aligned}
$$

The speed of MS accumulation in year $t$ is a constant of 45,139,172 tonnes/year and the previous period's value (a one lag period Auto-Regressive term) with a coefficient of 0.674 , and white noise $e_{t}$ ("random" or exogenous changes unexplained by the historical trends).

\section{Example 2.}

The model for Japan's level of material stocks is ARIMA(0,3,2):

$$
\begin{aligned}
& (1-B)^{3} y_{t}=\left(1-0.1682 B-0.6475 B^{2}\right) e_{t} \\
& (1-B)^{3} y_{t}=e_{t}-0.1682 e_{t-1}-0.6475 e_{t-2}
\end{aligned}
$$

The level of stock at time $t$ is a re-integrated (undifferenced) third order of difference of $y_{t}$ explained by a lag-1 Moving-Average term with a coefficient of -0.1682 and a lag 2 MovingAverage term with a coefficient of -0.6475 and white noise.

\section{References}

(1) Hyndman, R. J.; Khandakar, Y. Automatic Time Series Forecasting: The forecast Package for R. J. Stat. Softw. 2008, 27 (3), 1-22.

(2) Hyndman, R. J.; Athanasopoulos, G. Forecasting: principles and practice; OTexts, 2014. 


\section{Comparison of this study's stochastic forecasts with deterministic forecasts from previous research}

Fishman et al. 2014 presented "what-if" deterministic scenarios for the accumulation of construction mineral stocks in Japan and the United States for 2005 onwards.

Scenario 1 assumes that in all consecutive years, inflows will be equal to the average of 1995-2005. Scenario 2 assumes that inflow rates will change coupled to projected population rate changes.

In order to assess the ARIMA forecasts, we run the ARIMA forecasts of Japan and the USA from 2005 instead of from 2010 as in the main study, and compare the outputs to Fishman et al.'s results as well as to the real statistics of 2005-2010 presented in the figure below.

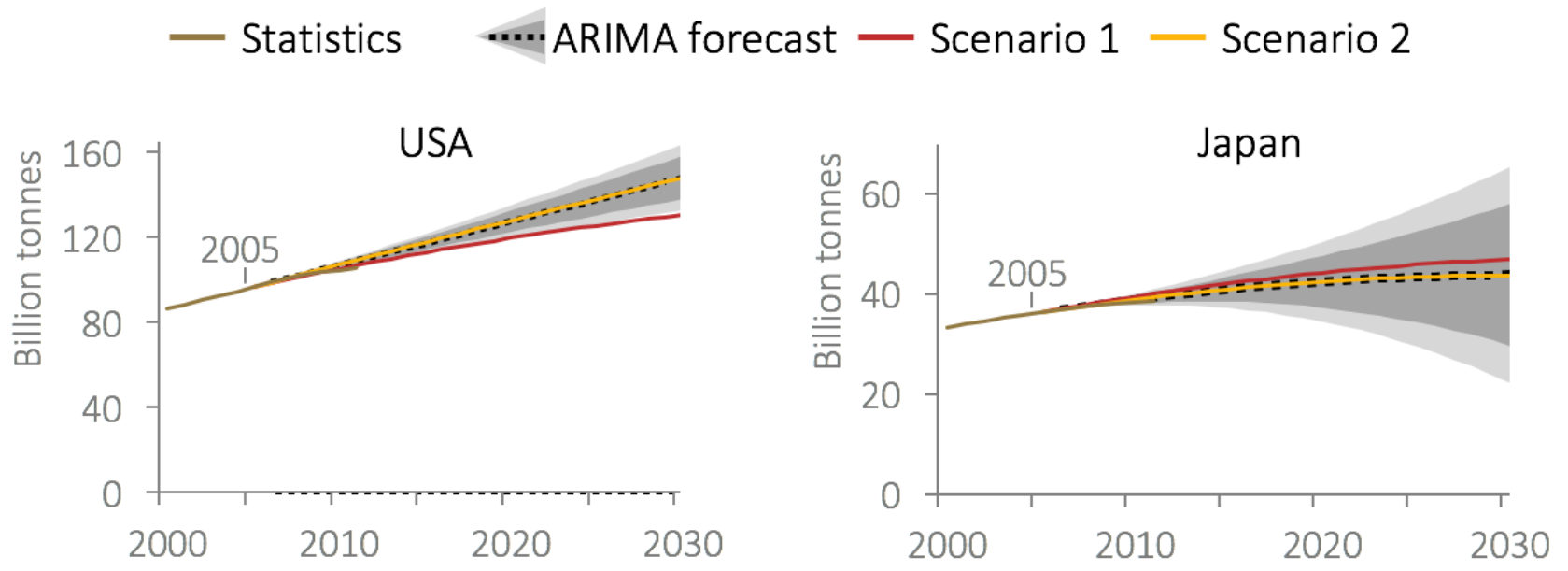

Remarkably, in both countries the ARIMA point forecasts were found to closely resemble the results obtained by the deterministic scenario 2. In the USA, Scenario 1 is at the bottom $95 \%$ confidence interval of the ARIMA forecast, while in Japan it is slightly above the point forecast and within the $80 \%$ intervals. In both the United States and in Japan, both the stochastic and deterministic results were found to be slightly overshooting the actual real-world statistics of 20052010, due to the 2008 crisis which neither methodology could account for. We conclude that the ARIMA method can provide reasonable results, comparable to those of deterministic methods.

\section{Reference}

(1) Fishman, T.; Schandl, H.; Tanikawa, H.; Walker, P.; Krausmann, F. Accounting for the Material Stock of Nations. Journal of Industrial Ecology 2014, 18 (3), 407-420. 
3. Visualization of the 3rd order of difference for Japan

The $3^{\text {rd }}$ order of difference from the levels series measures the change in acceleration, or "surge" in mater ial stock accumu lation. Historical data 1950-2010 and forecasted 2010-2030, with forecast intervals of $80 \%$ and $95 \%$.

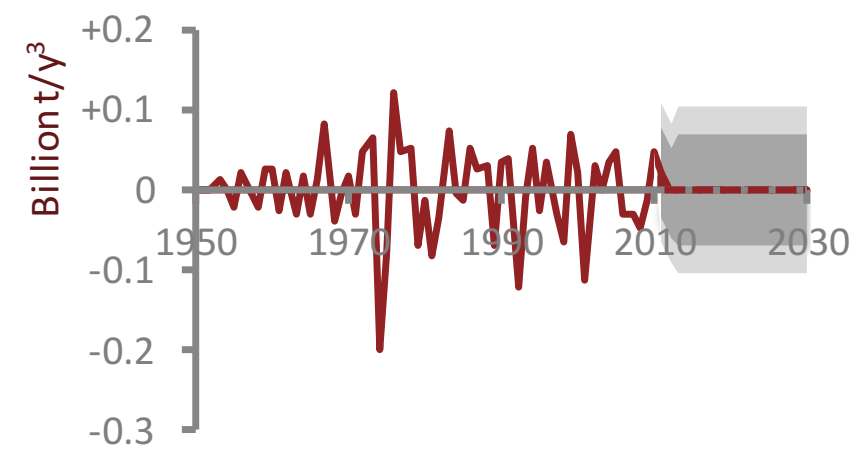

4. ARIMA models for all 45 examined countries and the world

For every country the following is provided:

1. Figure of the speed series. Historical data 1950-2010 (USA and Japan) and 1970-2010 (all other countries and the World) and forecasted 2010-2030, with forecast intervals of $80 \%$ and $95 \%$.

2. The ARIMA(p,d,q) model specification. $d$ is the number of differences from the speed series.

3. Table of the model's terms, their coefficients and their standard errors.

4. Notes, if applicable

Country models are presented by category and within by alphabetical order. Note the different vertical scales.

\subsection{Category I- stationary speed (one country)}

I.1 The Netherlands

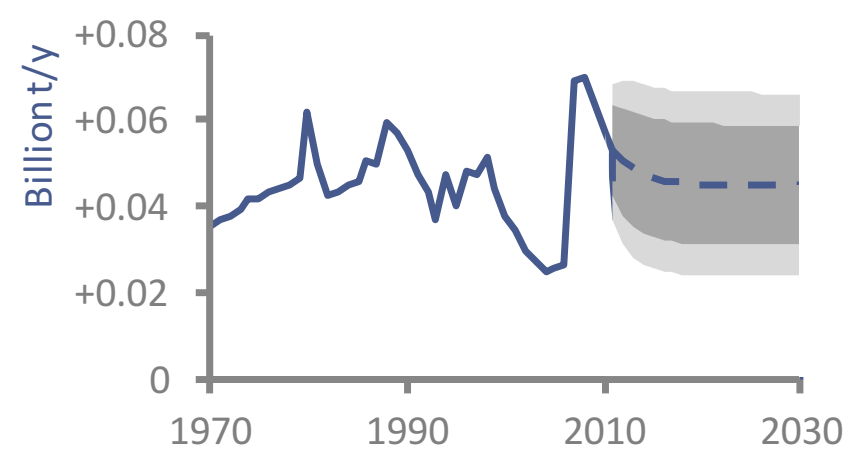

$\operatorname{ARIMA}(1,0,0)$ with non-zero mean

$\begin{array}{cr}\text { AR(1) } & \text { Intercept } \\ 0.674 \quad 45139172\end{array}$

Coefficient $\quad 0.674 \quad 45139172$

Standard Error $\quad 0.1145 \quad 3666545$ 


\subsection{Category II - stationary acceleration ( 20 countries)}

II.1 Argentina

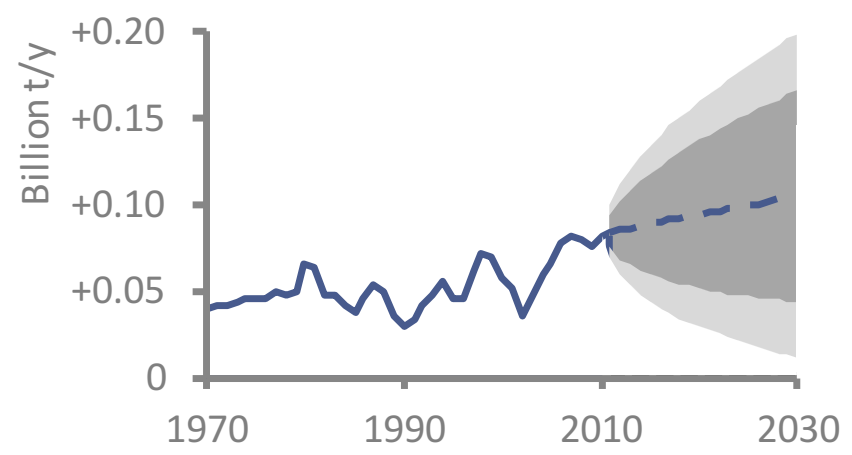

$\operatorname{ARIMA}(0,1,1)$ with drift

\begin{tabular}{rrr} 
& MA(1) & Drift \\
\hline Coefficient & 0.4394 & 1093932 \\
Standard Error & 0.1542 & 1699479
\end{tabular}

II.3 Bangladesh

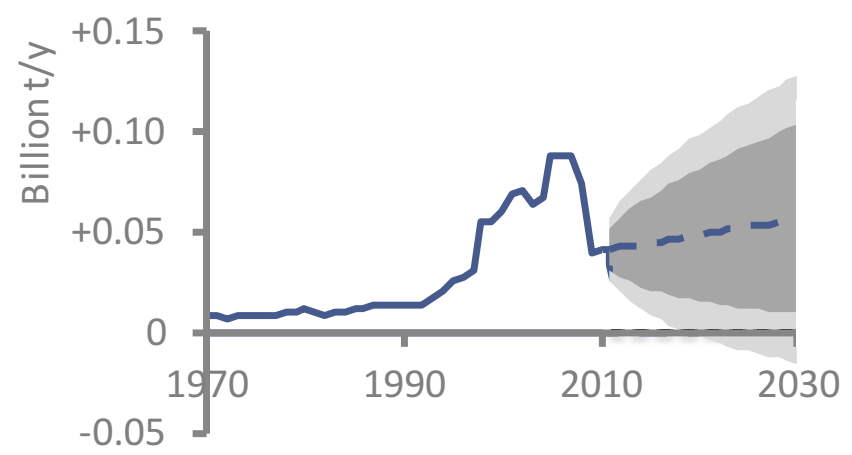

$\operatorname{ARIMA}(0,1,0)$ with drift

Drift

$\begin{array}{rr}789150 \\ \text { Coefficient } \\ \text { Standard Error } & 1289089\end{array}$

II.2 Australia

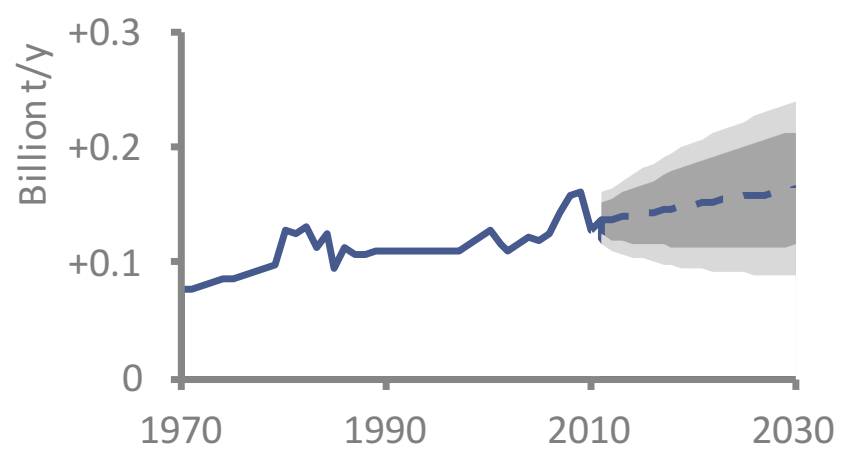

$\operatorname{ARIMA}(1,1,0)$ with drift

\begin{tabular}{rrr} 
& AR(1) & Drift \\
\hline Coefficient & -0.2889 & 1474016 \\
Standard Error & 0.1755 & 1361527
\end{tabular}

II.4 Colombia

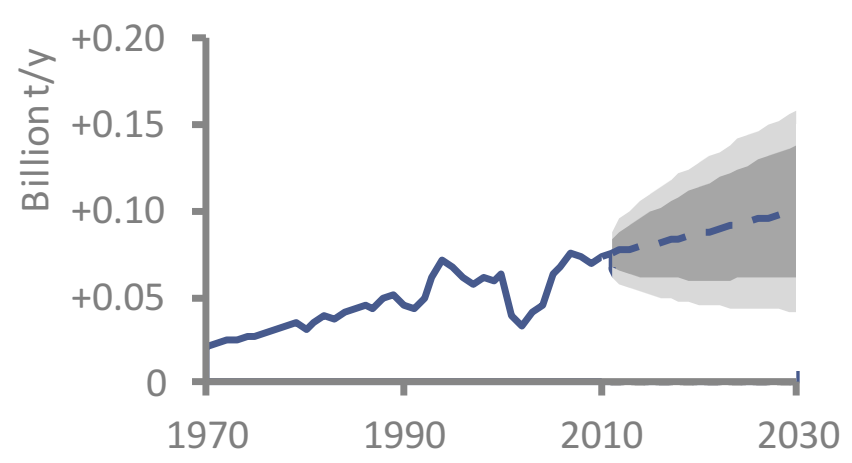

$\operatorname{ARIMA}(0,1,0)$ with drift

Drift

Coefficient 1311650

Standard Error 1046415 


\subsection{Category II, continued}

II.5 Indonesia

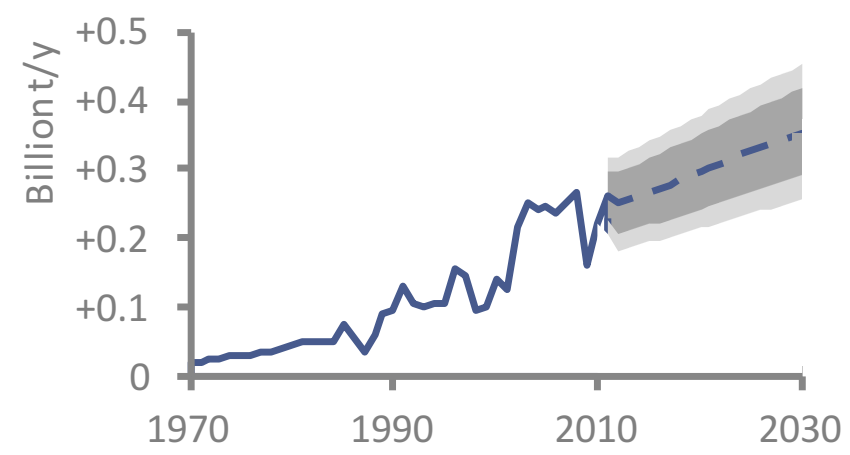

$\operatorname{ARIMA}(0,1,2)$ with drift

\begin{tabular}{rrrr} 
& MA(1) & MA(2) & Drift \\
\hline Coefficient & -0.2649 & -0.43225790536 \\
Standard Error & 0.1742 & 0.19931503771
\end{tabular}

II.7 Mexico

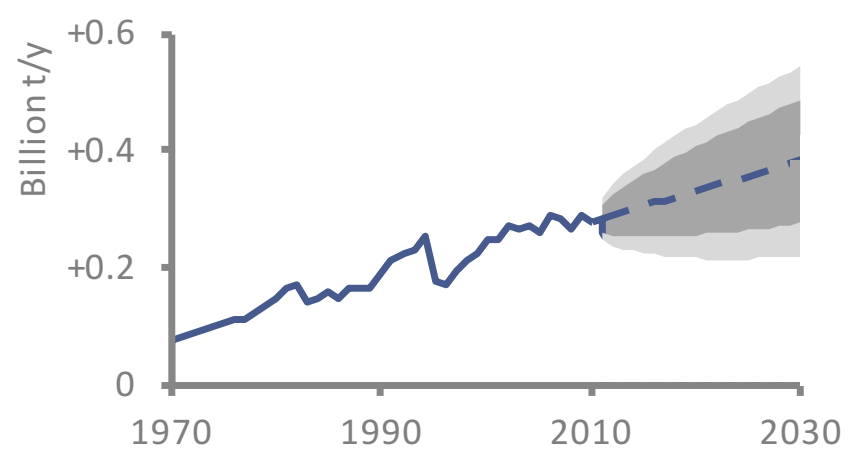

$\operatorname{ARIMA}(0,1,0)$ with drift

Drift

Coefficient 5062125

Standard Error 2908469
II.6 Malaysia

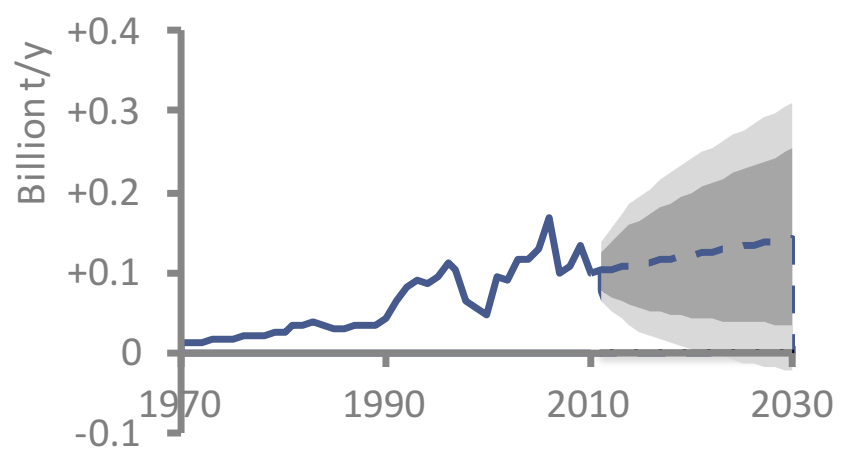

$\operatorname{ARIMA}(0,1,0)$ with drift

Drift

Coefficient 2225500

Standard Error 3009882

II.8 Morocco

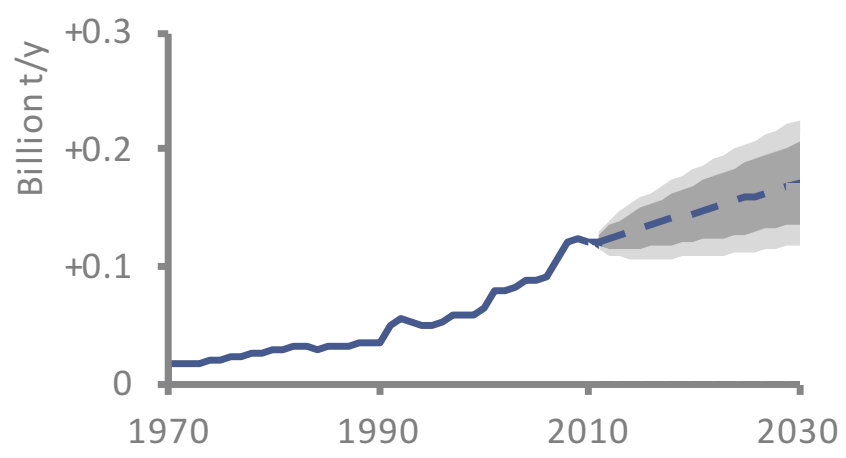

$\operatorname{ARIMA}(0,1,1)$ with drift

\begin{tabular}{rrr} 
& MA(1) & Drift \\
\hline Coefficient & 0.4618 & 2564557 \\
Standard Error & 0.1497 & 964276
\end{tabular}




\subsection{Category II, continued}

II.9 Myanmar

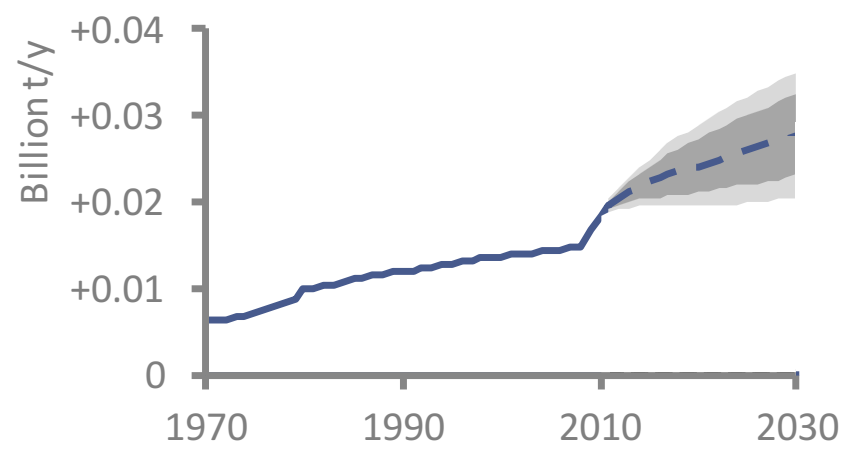

$\operatorname{ARIMA}(1,1,0)$ with drift

\begin{tabular}{rrr} 
& AR(1) & Drift \\
\hline Coefficient & 0.6352 & 354093 \\
Standard Error & 0.1579 & 139369
\end{tabular}

II.11 Nigeria

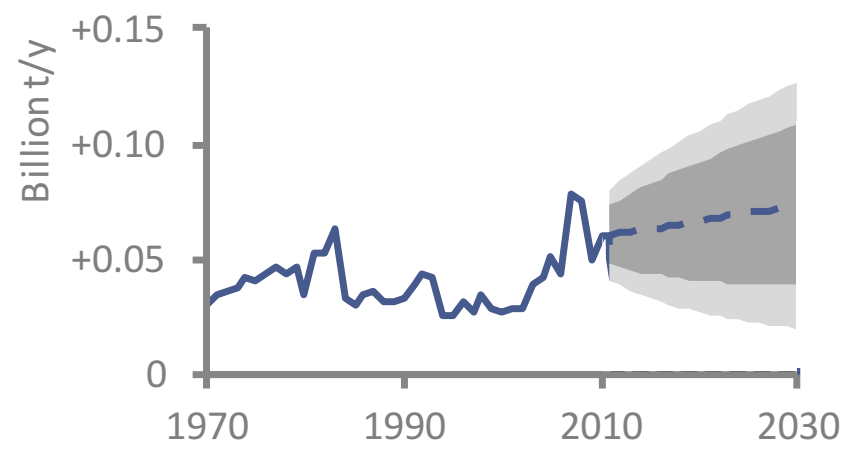

$\operatorname{ARIMA}(0,1,1)$ with drift

\begin{tabular}{rrr} 
& MA(1) & Drift \\
\hline Coefficient & -0.4125 & 684738 \\
Standard Error & 0.1683 & 938341
\end{tabular}

II.10 Nepal

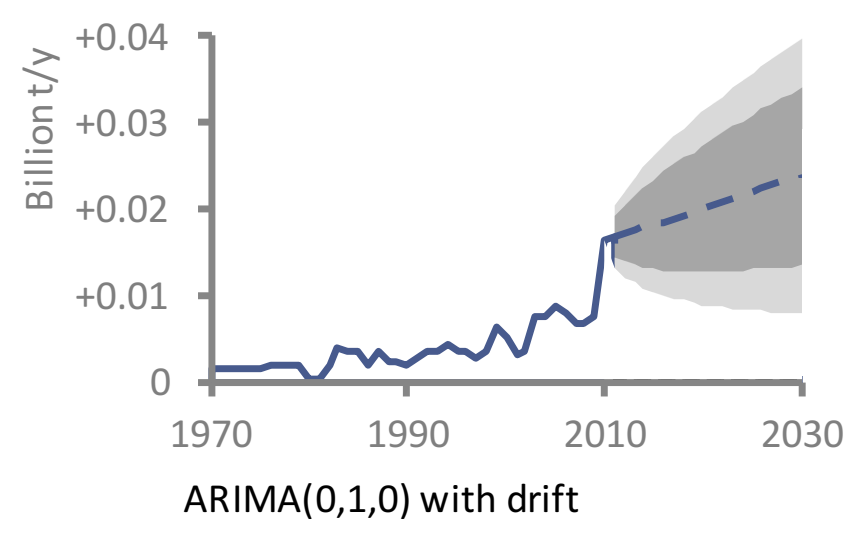

Drift

Coefficient 370850

Standard Error $\quad 284508$

II.12 The Philippines

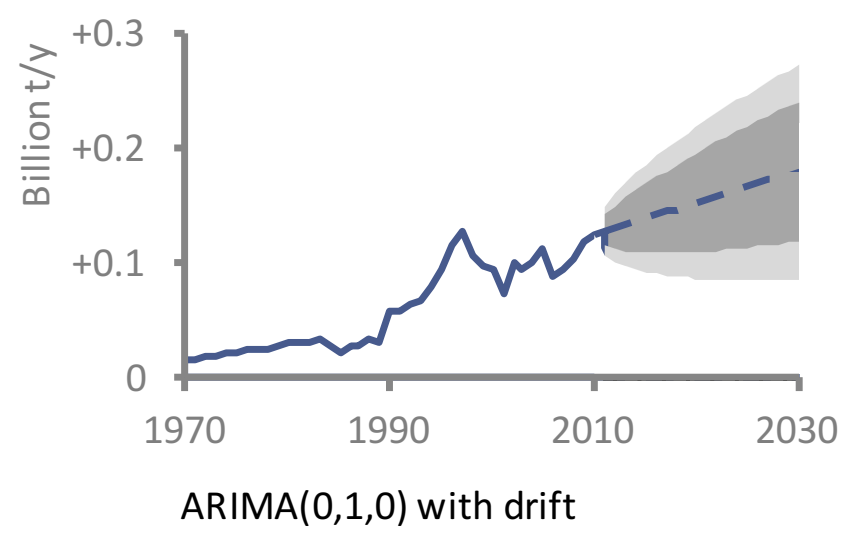

Drift

Coefficient 2714900

Standard Error 1679422 


\subsection{Category II, continued}

\section{II.13 Romania}

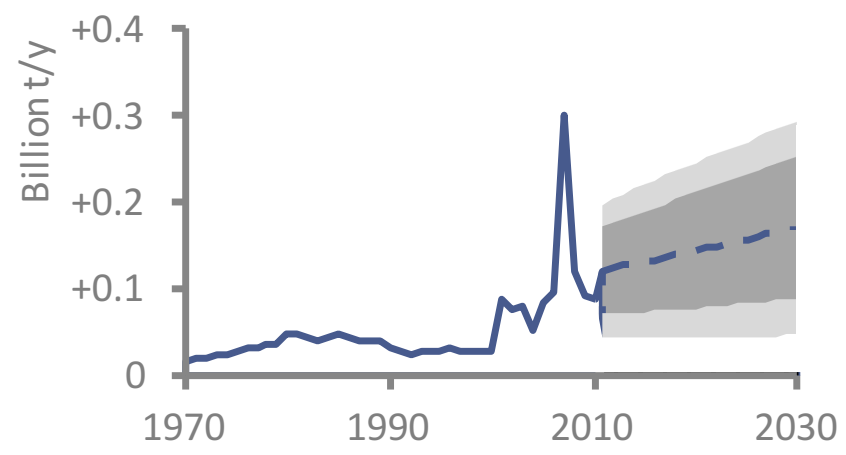

$\operatorname{ARIMA}(0,1,1)$ with drift

\begin{tabular}{rrr} 
& MA(1) & Drift \\
\hline Coefficient & -0.7133 & 2591781 \\
Standard Error & 0.1248 & 1912162
\end{tabular}

II.15 Spain

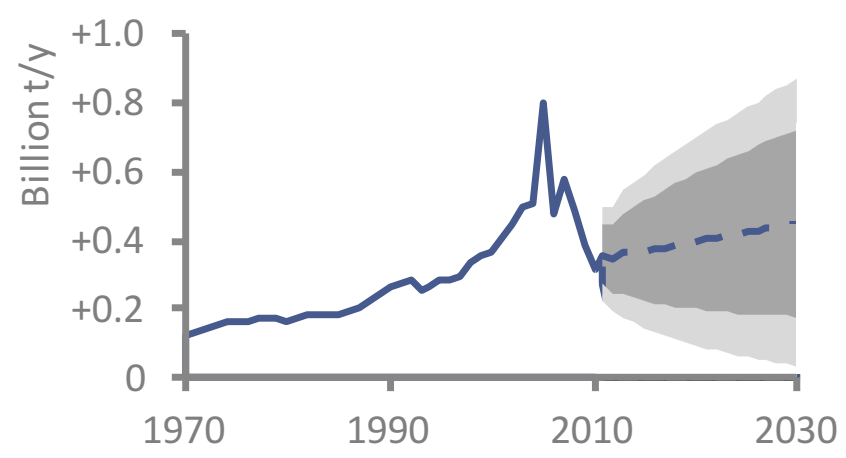

$\operatorname{ARIMA}(1,1,0)$ with drift

\begin{tabular}{rrr} 
& AR(1) & Drift \\
\hline Coefficient & -0.4761 & 5432756
\end{tabular}

Standard Error $\quad 0.1393 \quad 7458879$
II.14 South Africa

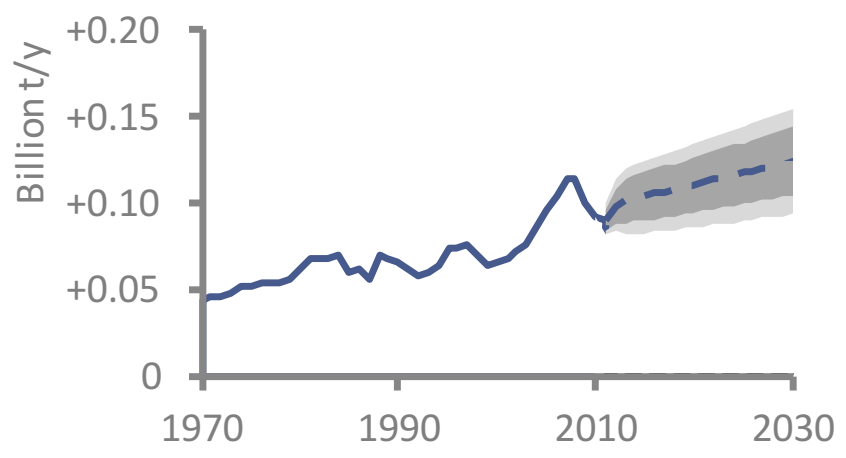

$\operatorname{ARIMA}(0,1,3)$ with drift

\begin{tabular}{rrrrr} 
& $\operatorname{MA}(1)$ & $\operatorname{MA}(2)$ & $\operatorname{MA}(3)$ & Drift \\
\hline Coefficient & 0.2676 & 0.1076 & -0.7782 & 1331001 \\
S.E. & 0.2217 & 0.2457 & 0.3713 & 490330
\end{tabular}

II.16 Sri Lanka

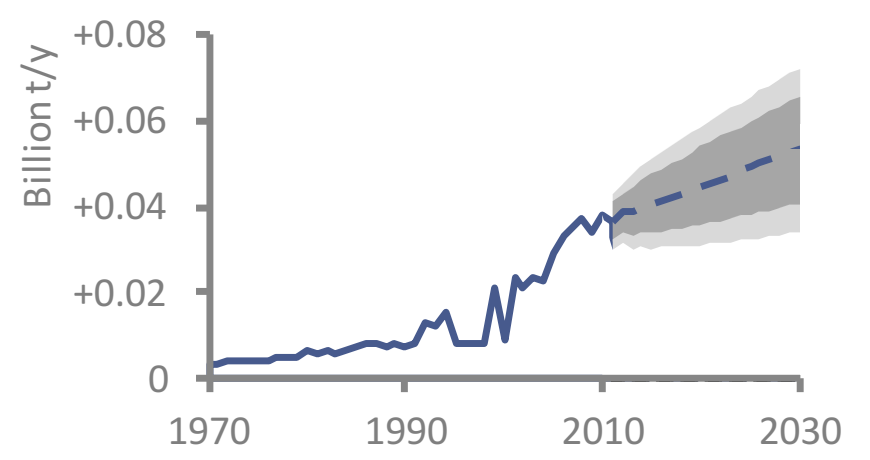

$\operatorname{ARIMA}(1,1,0)$ with drift

\begin{tabular}{rrr} 
& AR(1) & Drift \\
\hline Coefficient & -0.5935 & 826856 \\
Standard Error & 0.1257 & 332334
\end{tabular}




\subsection{Category II, continued}

II.17 Thailand

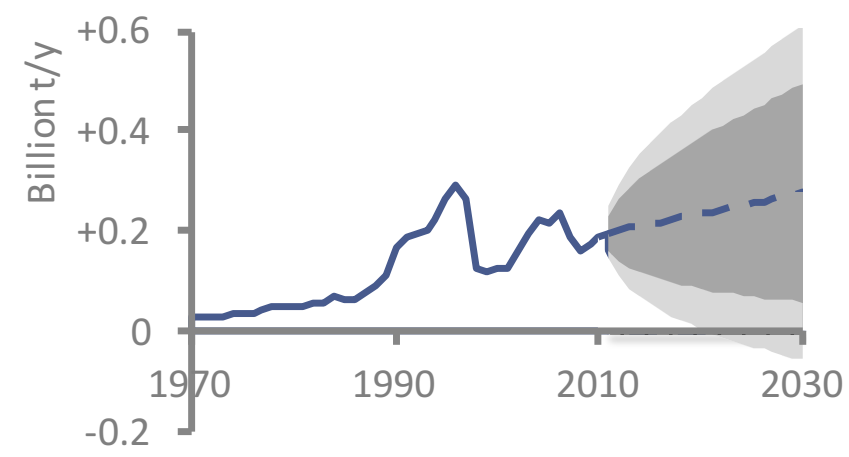

$\operatorname{ARIMA}(0,1,1)$ with drift

\begin{tabular}{rrr} 
& MA(1) & Drift \\
\hline Coefficient & 0.4046 & 4164549 \\
Standard Error & 0.1478 & 6034122
\end{tabular}

II.19 Venezuela

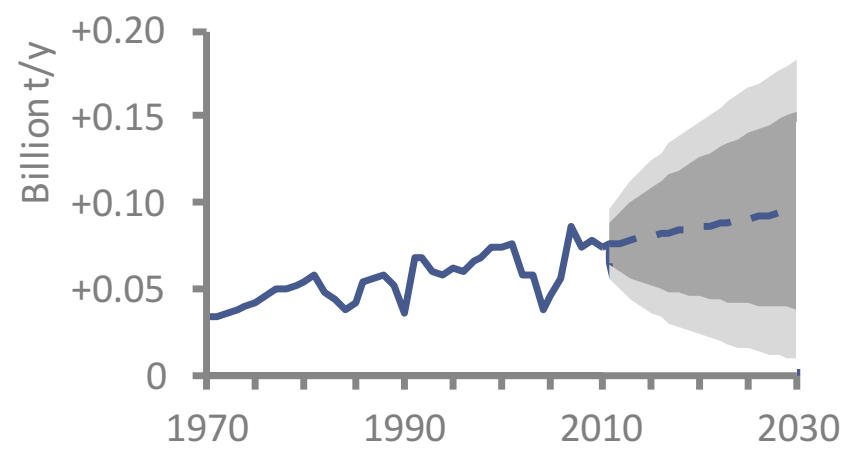

$\operatorname{ARIMA}(0,1,0)$ with drift

Drift

Coefficient 1035950

Standard Error 1569190
II.18 Turkey

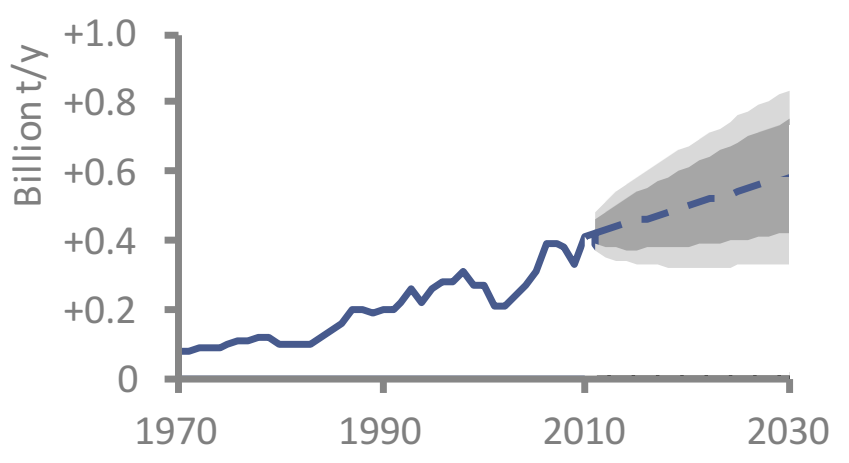

$\operatorname{ARIMA}(0,1,0)$ with drift

Drift

\begin{tabular}{rr}
\hline Coefficient & 8507525 \\
Standard Error & 4515892
\end{tabular}

II.20 USA

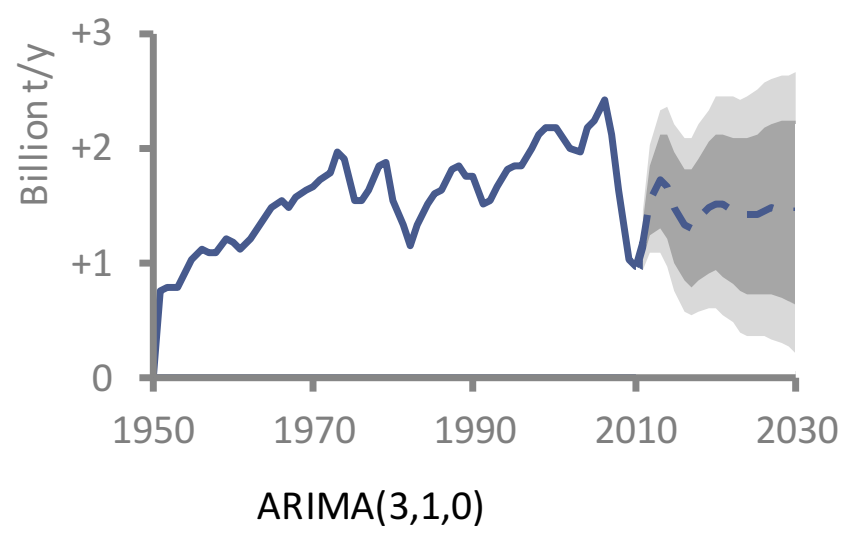

$\mathrm{AR}(1) \quad \mathrm{AR}(2) \quad \mathrm{AR}(3)$

Coefficient $0.5436-0.1846 \quad-0.3595$

$\begin{array}{llll}\text { Standard Error } \quad 0.124 & 0.1545 & 0.1425\end{array}$

Notes for the USA:

1. The ARIMA model selection was conducted on the Levels series, whose model is $\operatorname{ARIMA}(3,2,0)$. The coefficients are by definition the same.

2. Note the longer horizontal (time) axis. 
4.3. Category III - non-stationary acceleration, overall increasing acceleration (15 countries + World)

III.1 Afghanistan

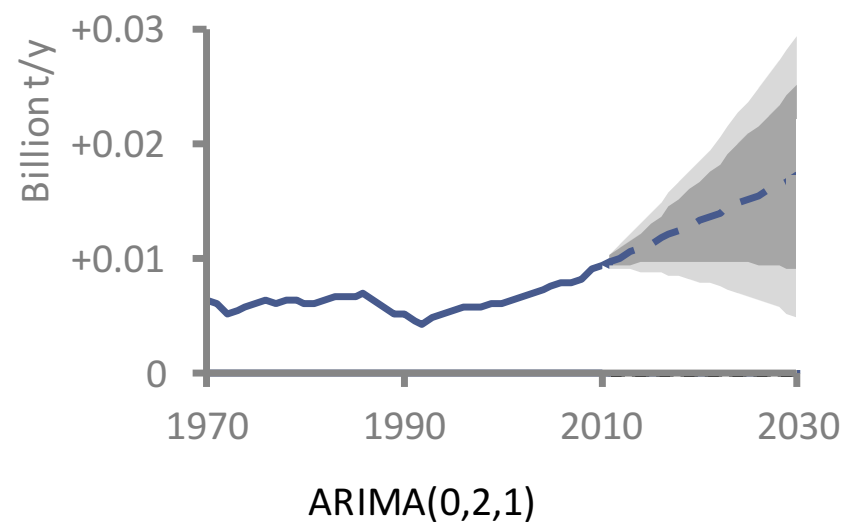

\begin{tabular}{rr} 
& MA(1) \\
\hline Coefficient & -0.7265 \\
Standard Error & 0.1795
\end{tabular}

III.3 Brazil

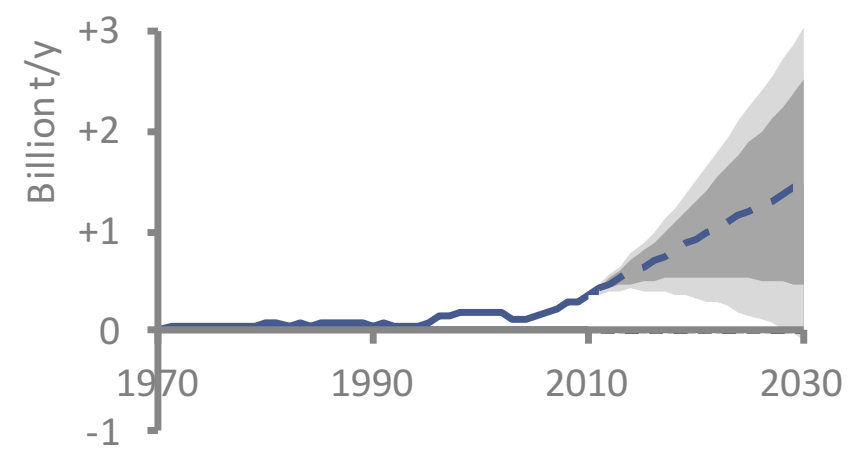

$\operatorname{ARIMA}(1,2,0)$

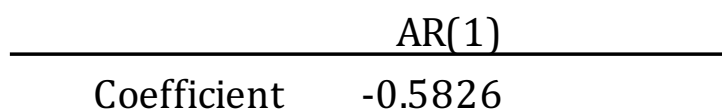

Standard Error $\quad 0.1523$
III.2 Algeria

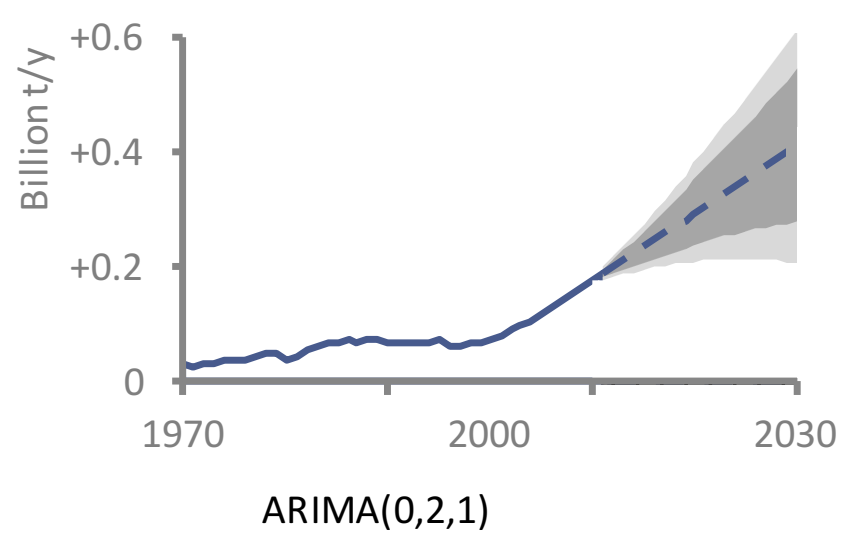

MA(1)

Coefficient $\quad-0.7156$

Standard Error $\quad 0.0996$

III.4 China

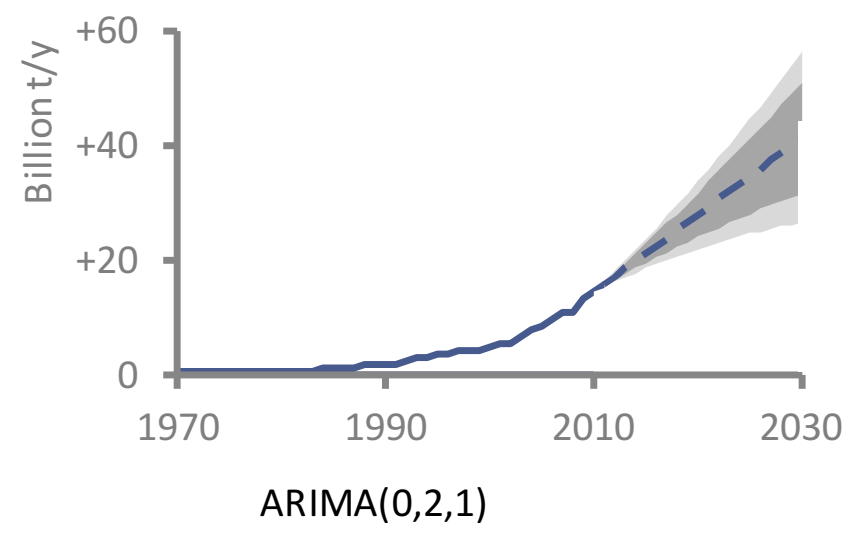

MA(1)

Coefficient $\quad-0.571$

Standard Error $\quad 0.1154$ 


\subsection{Category III, continued}

III.5 DR Congo

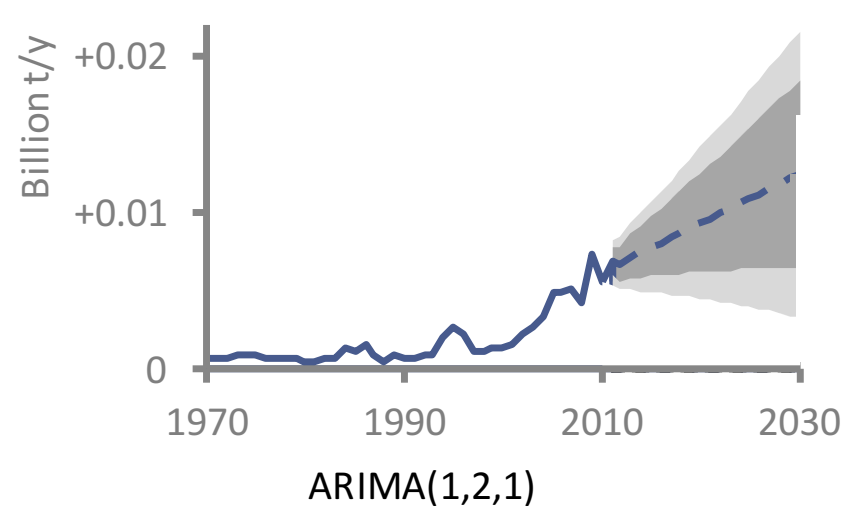

\begin{tabular}{rrr} 
& $\mathrm{AR}(1)$ & $\mathrm{MA}(1)$ \\
\hline Coefficient & -0.4376 & -0.8987 \\
Standard Error & 0.1746 & 0.0873
\end{tabular}

III.7 India
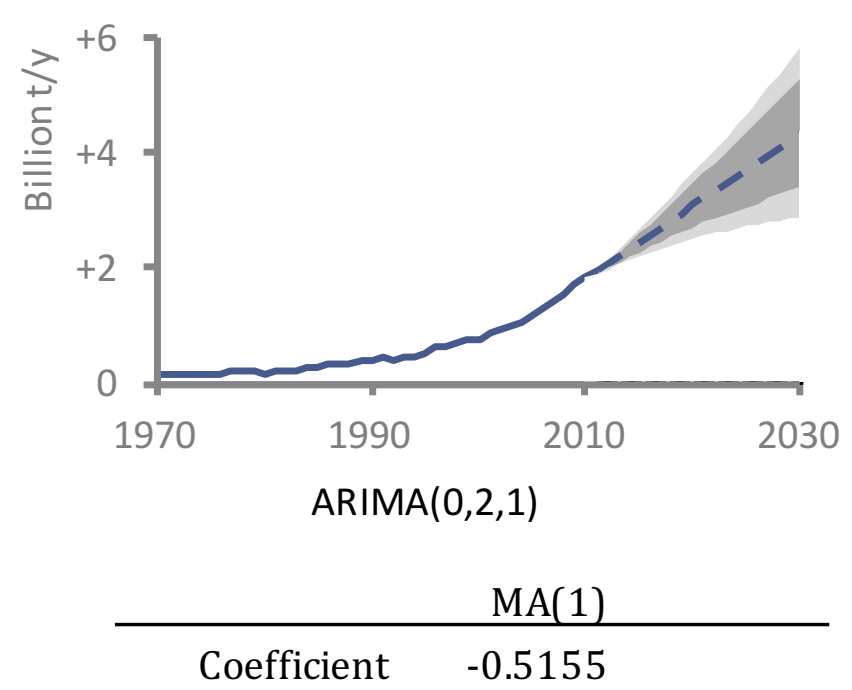

Standard Error $\quad 0.1363$
III.6 Ethiopia

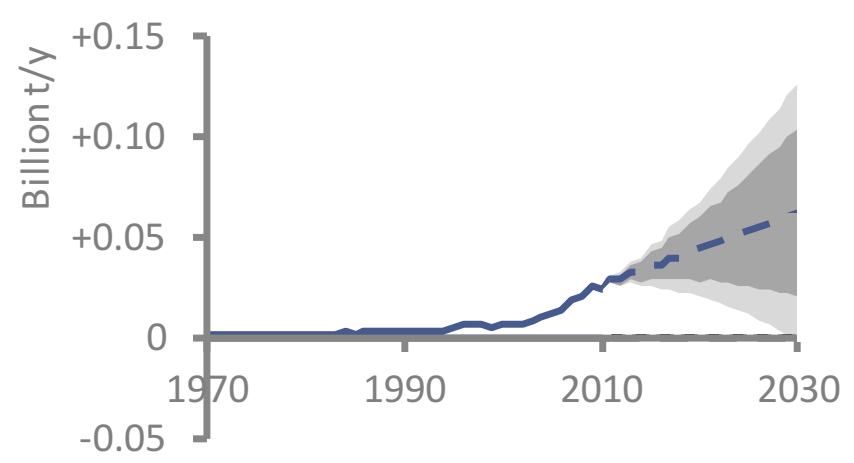

$\operatorname{ARIMA}(1,2,0)$

\begin{tabular}{rr} 
& \multicolumn{1}{c}{ AR(1) } \\
\hline Coefficient & -0.9046 \\
Standard Error & 0.0941
\end{tabular}

III.8 Iran

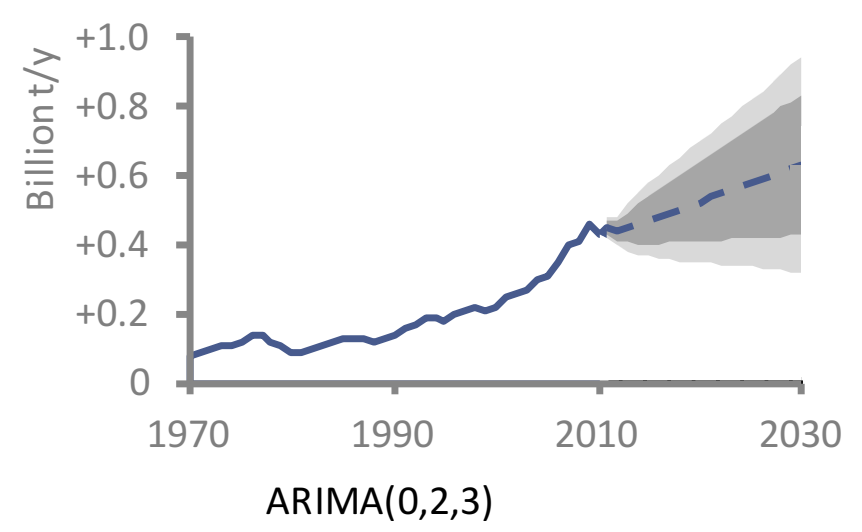

\begin{tabular}{rrrr} 
& $\mathrm{MA}(1)$ & $\mathrm{MA}(2)$ & $\mathrm{MA}(3)$ \\
\hline Coefficient & -0.9085 & 0.5565 & -0.5734 \\
Standard Error & 0.1586 & 0.1991 & 0.1408
\end{tabular}




\subsection{Category III, continued}

III.9 Kenya

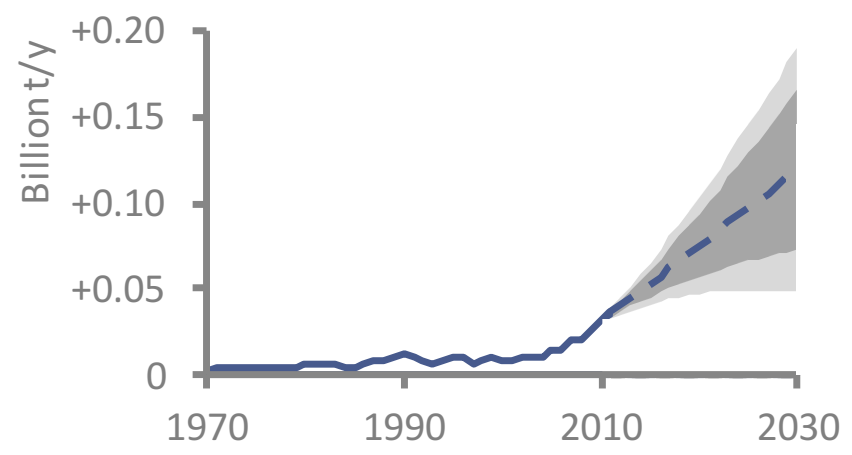

$\operatorname{ARIMA}(0,2,2)$

\begin{tabular}{rrr} 
& $\mathrm{MA}(1)$ & $\mathrm{MA}(2)$ \\
\hline Coefficient & -0.991 & 0.3259 \\
Standard Error & 0.1562 & 0.1473
\end{tabular}

III.11 Poland

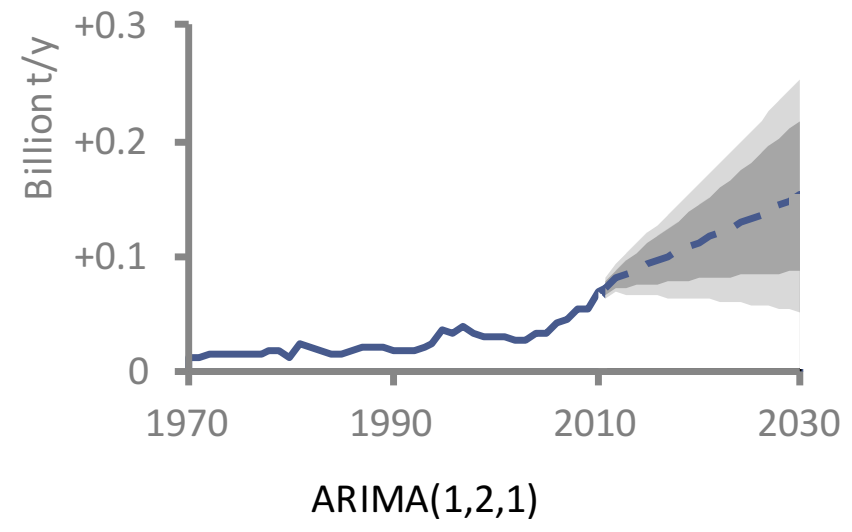

\begin{tabular}{rrr} 
& $\mathrm{AR}(1)$ & $\mathrm{MA}(1)$ \\
\hline Coefficient & 0.3551 & -0.8946 \\
Standard Error & 0.1938 & 0.1148
\end{tabular}

III.10 Pakistan

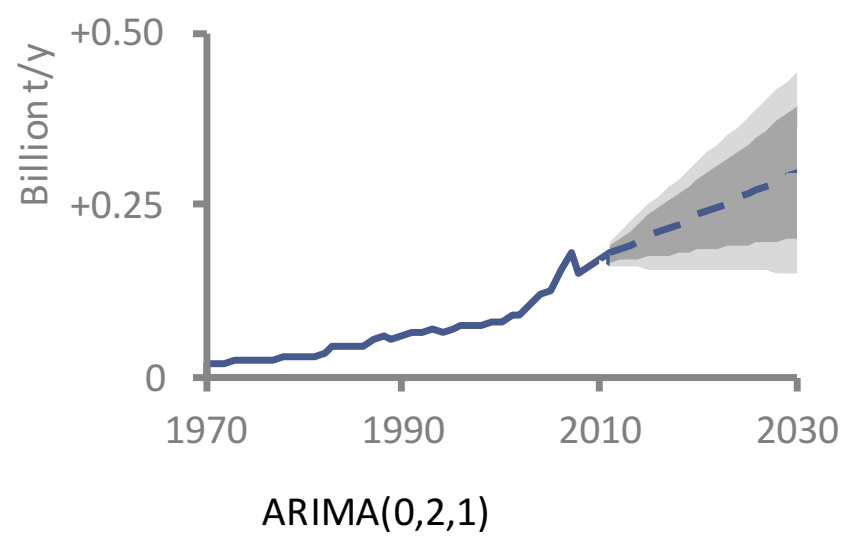

$\mathrm{MA}(1)$

Coefficient $\quad-0.9149$

Standard Error $\quad 0.0755$

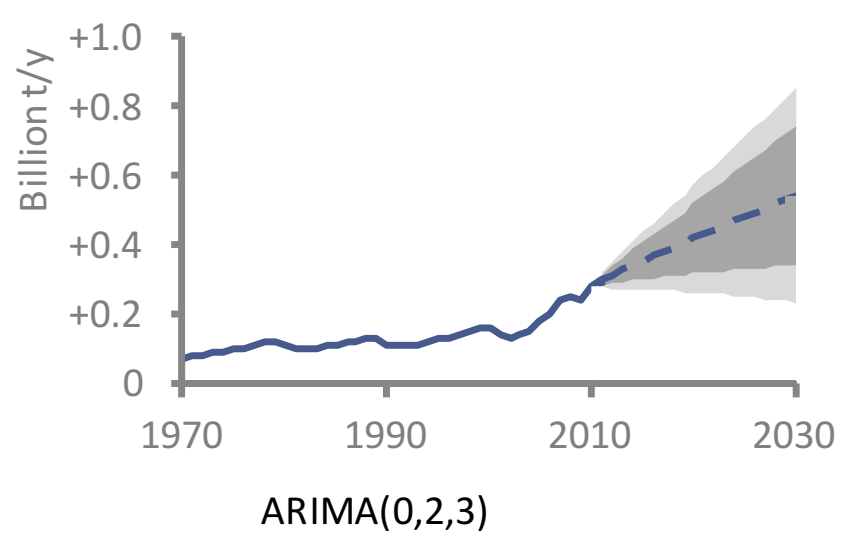

$\mathrm{MA}(1) \quad \mathrm{MA}(2) \quad \mathrm{MA}(3)$

$\begin{array}{llll}\text { Coefficient } & -0.945 & 0.4931 & -0.4\end{array}$

Standard Error $\quad 0.1572 \quad 0.1981 \quad 0.1705$ 


\subsection{Category III, continued}

III.13 Sudan
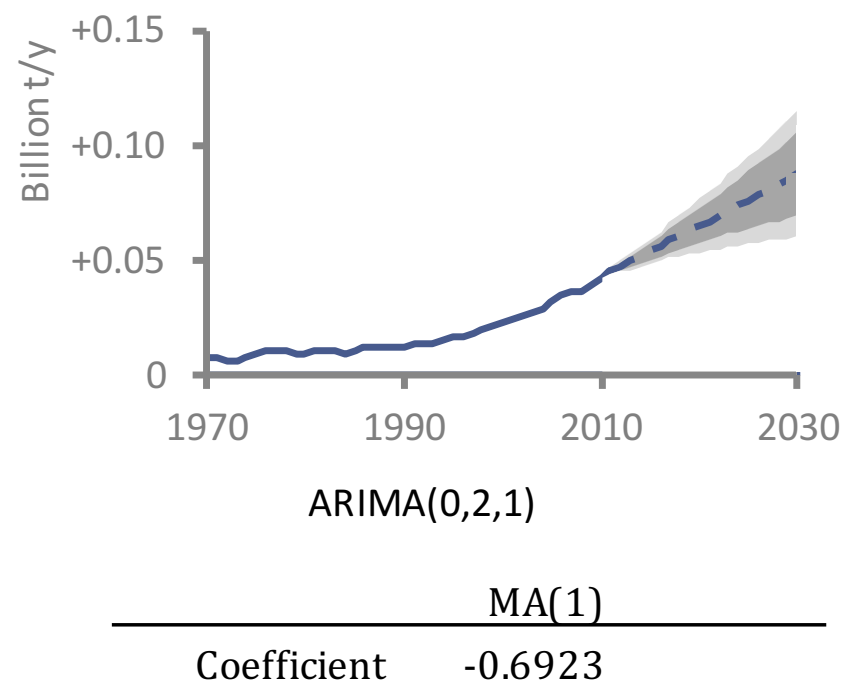

Standard Error $\quad 0.1075$

III.15 Vietnam

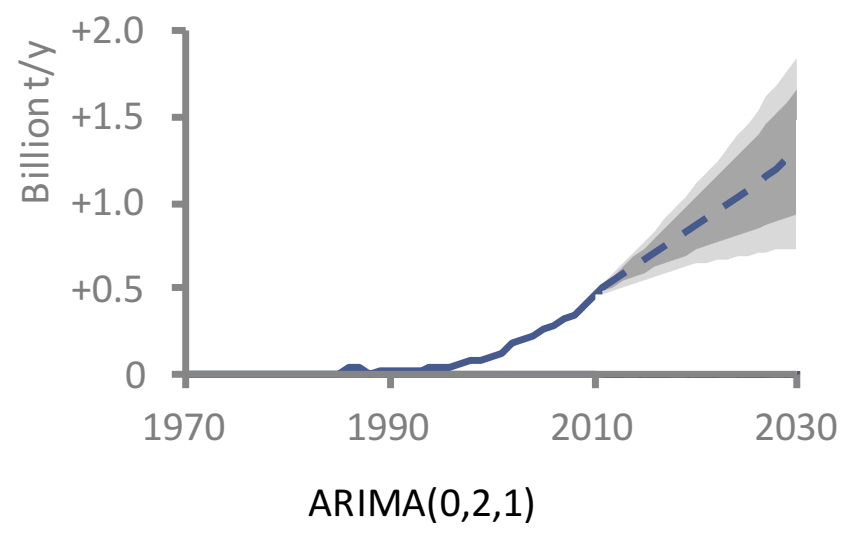

\begin{tabular}{cc} 
MA(1) \\
\hline Coefficient & -0.6999
\end{tabular}

Standard Error $\quad 0.0967$
III.14 Tanzania

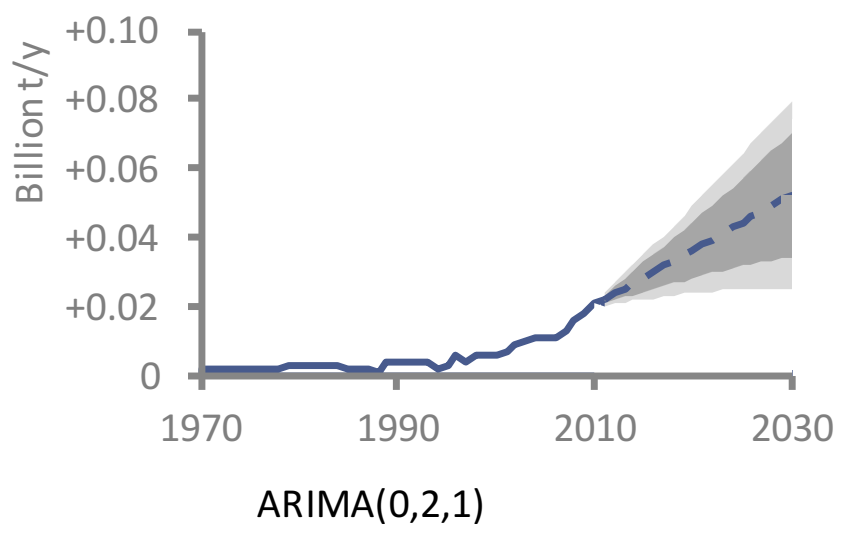

$\mathrm{MA}(1)$

Coefficient $\quad-0.8137$

Standard Error $\quad 0.087$

III.16 the World

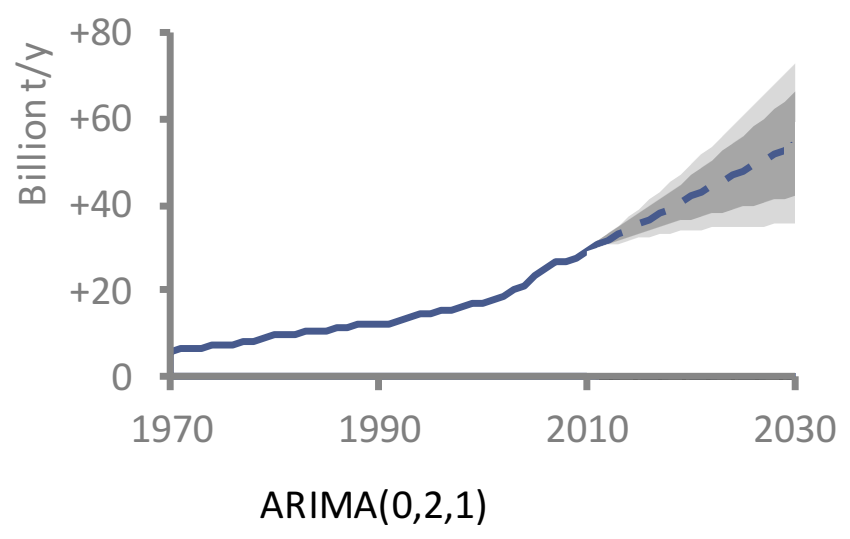

$\operatorname{MA}(1)$

Coefficient $\quad-0.6554$

Standard Error $\quad 0.1573$ 
IV.1 Canada

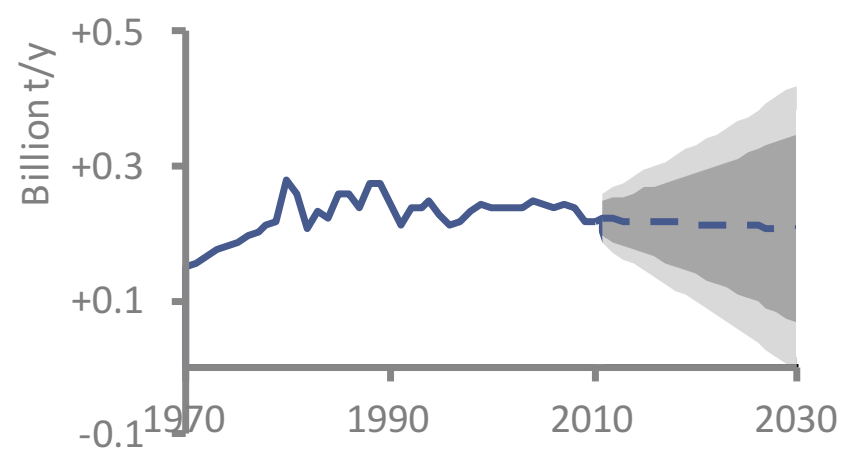

$\operatorname{ARIMA}(2,2,1)$

$\mathrm{AR}(1) \quad \mathrm{AR}(2) \quad \mathrm{MA}(1)$

$\begin{array}{llll}\text { Coefficient } & -0.169 & -0.3082 & -0.9178\end{array}$

$\begin{array}{llll}\text { Standard Error } & 0.1573 & 0.1545 & 0.0838\end{array}$

IV.3 Germany

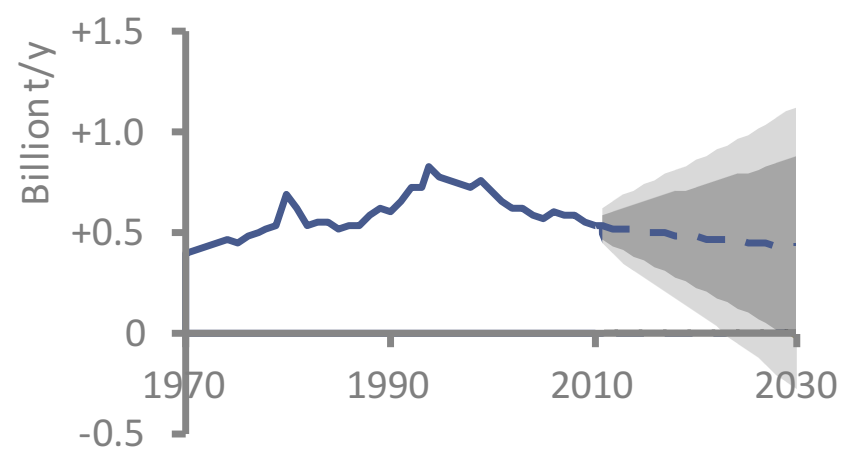

$\operatorname{ARIMA}(0,2,1)$

\begin{tabular}{cc} 
MA(1) \\
\hline Coefficient & -0.9249
\end{tabular}

Standard Error $\quad 0.0844$
IV.2 France

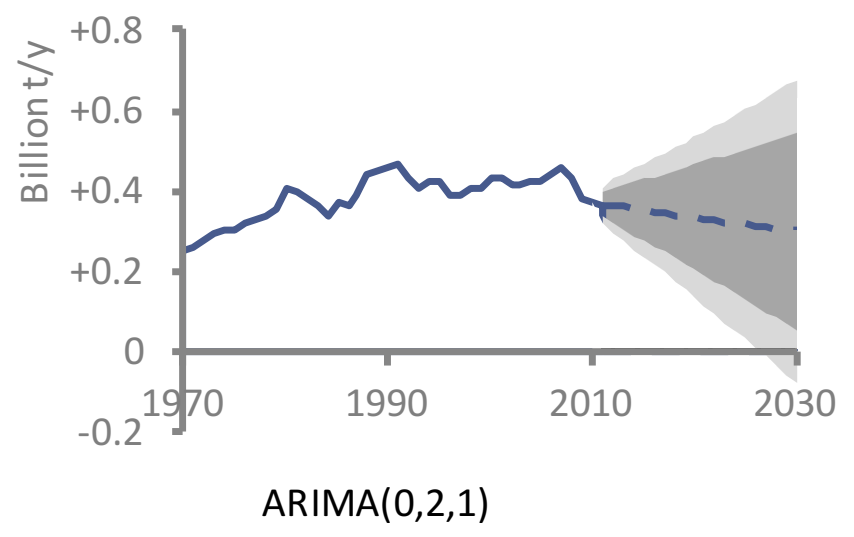

MA(1)

\begin{tabular}{rr}
\hline Coefficient & -0.9117 \\
Standard Error & 0.0834
\end{tabular}

IV.4 Italy

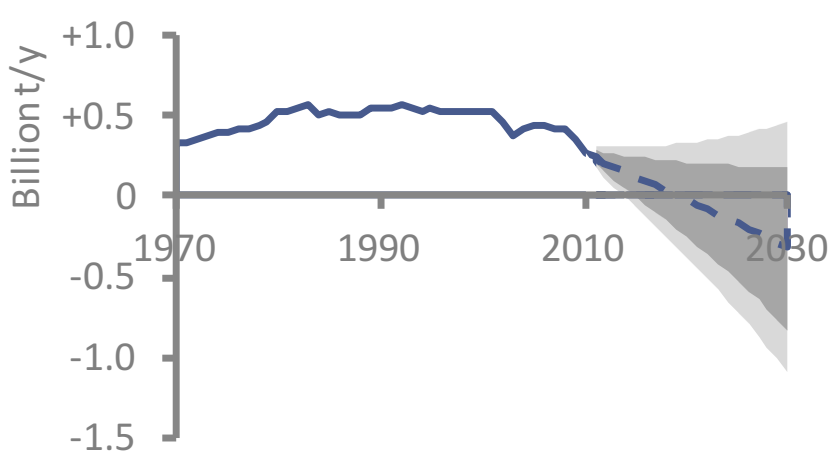

$\operatorname{ARIMA}(0,2,1)$

$\mathrm{MA}(1)$

Coefficient $\quad-0.8206$

Standard Error $\quad 0.1095$ 


\subsection{Category IV, continued}

IV.5 Japan

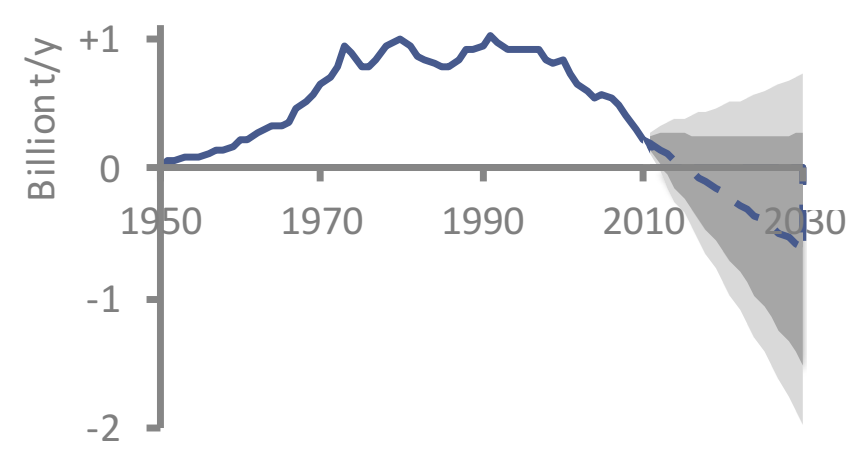

$\operatorname{ARIMA}(0,2,2)$

\begin{tabular}{rrr} 
& MA(1) & MA(2) \\
\hline Coefficient & -0.1682 & -0.6475 \\
Standard Error & 0.1066 & 0.1048
\end{tabular}

Notes for Japan:

1. The ARIMA model selection was conducted on the Levels series, whose model is $\operatorname{ARIMA}(0,3,2)$. The coefficients are by definition the same.

2. Note the longer horizontal (time) axis.

\section{IV.7 South Korea}

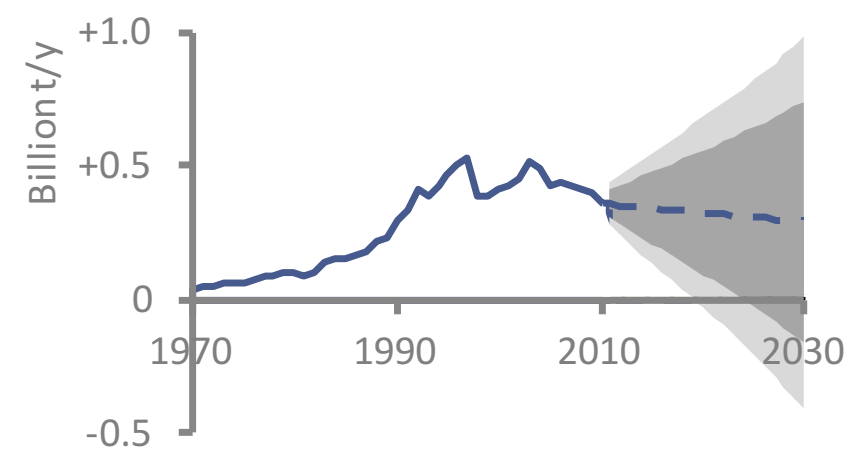

$\operatorname{ARIMA}(0,2,1)$

\section{$\mathrm{MA}(1)$}

\begin{tabular}{rr} 
& $\mathrm{MA}(1)$ \\
\hline Coefficient & -0.8978 \\
Standard Error & 0.1215
\end{tabular}

IV.6 North Korea

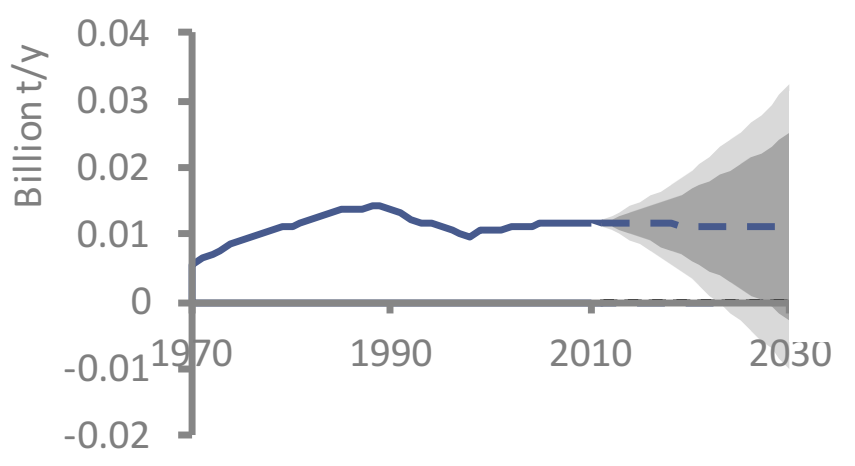

$\operatorname{ARIMA}(0,2,1)$

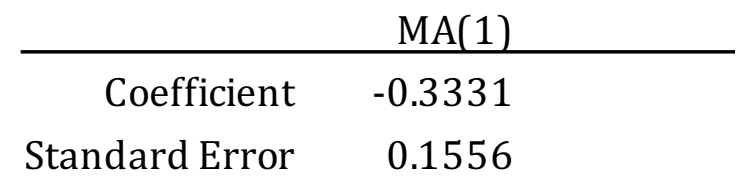

$\mathrm{MA}(1)$

0.1556
IV.8 The United Kingdom

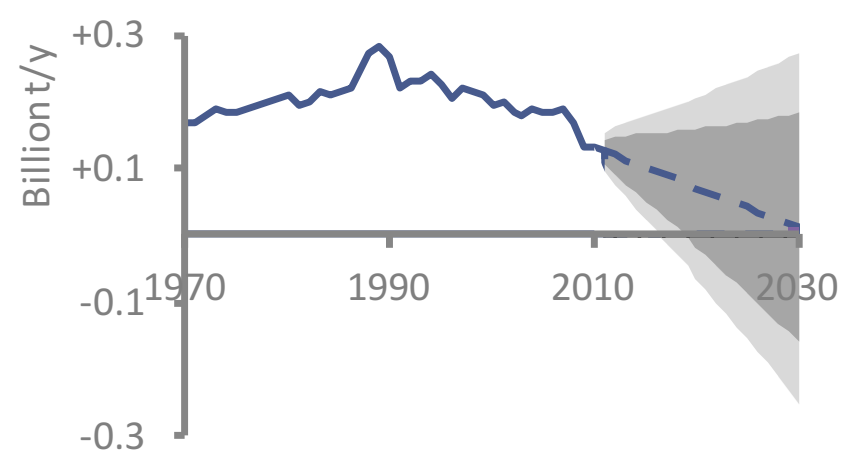

$\operatorname{ARIMA}(0,2,1)$

$\mathrm{MA}(1)$

\begin{tabular}{rr} 
& \multicolumn{1}{c}{$\mathrm{MA}(1)$} \\
\hline Coefficient & -0.9001 \\
Standard Error & 0.074
\end{tabular}

